\title{
Ethics and \\ Corporate Social Responsibility
}

\author{
Enrico Cavalieri*
}

\begin{abstract}
The ethics we find in companies contains the same elements as the ethics in the socio-economic context in which they operate.

The aspirations and ethical levels of companies operating in certain countries differ substantially from those of companies operating in other areas, where the defence of the environment, social welfare, human rights, cooperation, assistance are expected and offered to a lower degree, or are not requested or protected at all.

The new globalised, networked economy, based on the coordinated management of knowledge, sets evolutionary trends in motion that raise the level of ethicality, but simultaneously generates a braking effect on the ethical contents of corporate behaviour.
\end{abstract}

Keywords: Global Markets; Corporate Social Responsibility; Ethics; Transparency; Economic and Legislative Asymmetries

\section{Ethics and Global Markets}

There is a great deal of talk about 'business ethics', as if to say that what we could call 'autonomous' ethical concepts, generated by the logics and needs of the manufacturing context itself, can take shape and develop inside manufacturing organisations, but without parallels or correlations in the ethical concepts of society.

All this is unthinkable. The company is a system that is open to the environment, governed by persons who live in specific contexts and are the bearers, in their performance of the function of corporate governance, of the aspirations, culture and morality that characterise them, because they are part of a society that hopes for or conceals these values, and expresses them more or less strongly and consciously. The ethics we find in companies contains the same elements as the ethics in the socio-economic context in which they operate.

* Professor of Corporate Economics, University of Rome-Tor Vergata (enrico.cavalieri @uniroma2.it)

Cavalieri Enrico, Ethics and Corporate Social Responsibility, Symphonya. Emerging Issues in Management (symphonya.unimib.it), n. 2, 2007, pp. 24-34 
This initial awareness introduces the concept of the relativity of ethical behaviour, in time and space. The aspirations and ethical levels of companies operating in certain countries differ substantially from those of companies operating in other areas, where the defence of the environment, social welfare, human rights, cooperation, assistance, etc. are expected and offered to a lesser degree, or are not requested or protected at all.

Imagining universal ethics that might inspire a company's behaviour in the same way and to the same extent, regardless of where it operates, could be a dream, an inspiration for a still distant future, but unfortunately it has never been, and still cannot be a reality ${ }^{1}$.

This new globalised, networked economy, based on the coordinated management of knowledge, sets evolutionary trends in motion that raise the level of ethicality, but simultaneously generates a braking effect on the ethical contents of corporate behaviour. Evolutionary trends and braking effects are generated regardless of existing codes of practice, because they are linked to purely economical and social needs.

'This is, without doubt, the first time in history that legislation, which has regulated the capitalist regime for centuries, has appealed to external principles, or ethics to be more explicit, in such a massive way... And this is not to solve a single problem, but to find a global solution to the dysfunctions of a system that now appears uncontrollable. The motivations for these appeals differ each time, often confused and not always innocent, and they probably constitute a violent rejection of the ideological structure that has always sustained capitalism. The novel element is that the criticism is not coming from its enemies but from the very advocates of a system that has until now been proud of its self-sufficiency, even ideologically,2.

These considerations may help us to understand why the issue of ethics has become so pregnant with meaning.

\section{Evolutionary Trends}

\subsection{Transparency}

The first need we must refer to briefly is that of transparency, which is tending albeit slowly and with some opposition - to become an essential condition of access to and permanence on the markets, and not only financial markets, where resources should preferably be inspired by more efficient and virtuous manufacturing structures. Information is an important part of democratic life, because it allows us not only to make conscious choices, but also to prevent or stop every type of possible abuse by some parties over others. 


\subsection{Quality}

The second need regards quality, in the broadest sense of the term. It is a complex issue, which extends well beyond the need to produce and supply a product that meets defined standards and the customer's specific expectations in relation to the price paid. Quality directly affects the manufacturing logics of the entire chain, at all stages of value creation, according to the philosophy of Total Quality Management.

It appears obvious that the routes to the myriad forms of quality incorporate higher elements of ethicality than previous manufacturing logics, which only took these routes into marginal consideration. An organisation inspired by quality reveals elements of order, achieves a change in mentality, makes it possible to identify mistakes, dysfunctions and related responsibilities, and tries to maximise value creation and to render an optimal level of service.

All this acquires greater significance in an economy striving to develop products that are seen as services with a high value for the user, offered in place of or - very often - to supplement goods.

\subsection{Cooperation}

The issue of cooperation is certainly the most suggestive and important to assess the ethical aspects of a company's operations. Tabling a discussion on cooperation means tackling problems of great social import. We refer to the different forms of contacts, collaboration and alliances between manufacturing organisations of all shapes and sizes, which have abandoned the model of absolute autonomy and chosen to approach their manufacturing experience as part of broader systems, from which they draw a non-negligible part of the tangible and intangible assets necessary to develop the production combination and to sustain innovation, and to compete successfully with the possibility of survival on the global market.

So, when the logics of pure exchange leave space for those of systematic collaboration between parties, the ethical contents of the contract relationship (correctness of the parts in meeting their respective obligations) are overcome in favour of the unpredictable ethical (as well as innovative) potential that stems from dialogue, shared projects, risks and related responsibilities, and the production and exchange of ideas and knowledge.

But the issue of cooperation also affects the ways that decision-making models are created within organisations. We see a slow passage from relationships based exclusively on forms of hierarchy, on rules and rigidity, to more flexible relations that are oriented more freely to participation and shared responsibility.

\subsection{Protection of the Environment}

And finally, the need to protect the environment focuses our attention on the role played by society in defining companies' operating and strategic choices: growing 
concern about pollution levels has forced companies to adopt more thorough, precise policies, often innovative and complex, to protect the natural environment.

\section{The Braking Effects}

\subsection{Economic and Legislative Asymmetries on the Global Market}

The pressure of global competition, combined with the fact that in certain countries it is possible to implement production combinations investing fewer resources (savings in labour costs, taxation, financial charges) or with higher degrees of freedom (absence of constraints or presence of less stringent constraints), forces companies (and above all those defending cost leadership) to locate a large part of their activities (particularly manufacturing) in these countries, so that they can produce and operate with a competitive advantage (lower costs, easier access to resources).

It is very difficult, if not impossible, to imagine a company that decides not to take advantage of the economic and legislative asymmetries present in the global market; that decides to behave in a way that is more respectful of the environment, the dignity of work, etc. and therefore, substantially more expensive than others that are less ethical in absolute terms, but equally feasible, and have been (or can be) adopted by its competitors.

We do not want to justify or approve these choices, but simply to underline that they are 'contained' in the phenomenon of globalisation, that they are generally widespread and implemented not only by large multinational corporations, but also by smaller firms that locate their manufacturing activities where significant economies can be achieved. At least as long as these asymmetries continue to be easily exploitable and to represent a deciding factor for the company's viability.

We can therefore observe that companies that operate in areas with profound social differences tend to be what we could call 'multi-ethical' companies, because they tend to differentiate their levels of ethicality, at least in part, aligning them to those of the socio-economic contexts in which they operate, in many of which ethics are of marginal importance.

\subsection{The Group Structure}

The need to take advantage of asymmetries between the different areas of the global marketplace forces manufacturing concerns to structure themselves as groups. They use the group structure to evade and avoid both the codes of practice put in place to protect various interests (creditors, savers, etc.) and the ethical aspects that they embrace. 


\subsection{The Role of Finance}

Finance dominates the economy: the power of institutional investors (mutual funds, pension funds, insurance, etc.) exceeds worldwide GDP (over \$50,000 billion), which allows them to take control of any large multinational corporation.

Every day, money is looking for the highest possible return, and investors operate on the global financial market with speculative logics. Many institutional investors consider the purchase of a controlling interest as a speculative investment, to be sold off as soon as the market value of the shares rises; managers are therefore induced to adopt managerial policies designed to increase the value of shares in the short term, even if (as Rappaport ${ }^{3}$ maintains) these policies slash investments that are decisive for development, externalising costs and damages and putting the organisation's survival and future success at risk. The company is therefore seen as '... an articulated asset, one whose performance measurement is somehow similar to that of an investment in a bond or state security, in other words an investment that is subject to contingencies that are expressed by comparison with alternative economic opportunities. Although it can cater for the speculative interest of a few, or even of many stockholders, this logical consequence is certainly a long way from the idea of government of a complex system by stockholders involved in the important decisions, related to management and coordination' ${ }^{4}$.

As long as this situation (the exploitation of asymmetries in codes of practice, the improper use of the group structure, excessive intrusiveness of finance) dominates the global economy, it is very difficult to imagine ethical behaviour taking hold in the governance of organisations, in spite of evolutionary trends triggered by the need for transparency, quality, protection of the environment and the gradual spread of cooperative relationships between parties and between companies.

\section{Corporate Social Responsibility}

Organisations that operate in society help to determine or to slow down its economic and social growth. So it is logical to think that, just like any other entity, a company is responsible to the society that it belongs to and in which it operates.

We can therefore say that:

a) the global integration of corporate systems, public authorities, services and infrastructure, codes of practice and constraints aggravates the situations of inefficiency and insolvency, quality deficiencies and the many types of imbalance that can emerge in every manufacturing organisation. The repercussions do not only affect the survival of the individual organisation, but extend to the outside world by destroying the equilibrium of the network, the system (the chain) or the operating structure that the company belongs to. And this increases the responsibility of each unit in the system exponentially, making it more complex. Social responsibility has become more profound and complex because of the transformation from an economy based on monetary exchange between units that were at most poorly integrated, to an economy based on profound horizontal and vertical interaction between organisations; 
b) similar considerations can be applied to financing methods that are no longer channelled exclusively through banks (with the guarantees that sustained the relationship), but allow a direct, and much more risky, influx of financial resources from savers to companies. With the result that, in the case of entities that issue financial tools (on the global market), this increases out of all proportion the involvement of financiers who link their economies directly to that of the company financed, in the presence of quite significant asymmetries of information, which markets seem unable to reduce or to keep to an acceptable level of risk.

c) We believe that these clarifications help us to understand that the people running our companies ought to have a strong, pregnant sense of the responsibility of managing the vital interests and savings of an ever-growing number of individuals, who have established a bond with the manufacturing organisation, trusting in the professional skills and competence of its managers and the validity of its strategic plan.

$\square$ 'Governments, activists and the media have become adept at holding companies to account for the social consequences of their activities, ${ }^{, 5}$, with the negative effects generated by this attitude. This is why '... Corporate Social Responsibility (CSR) has emerged as an inescapable priority for business leaders in every country.'

We are prompted to comment critically on Porter's statements quoted above; the author maintains that business leaders can no longer avoid the problem of CSR, because public opinion is now aware of the social damage caused by the activities of manufacturing organisations. Turning this around, it means that only systematic pressure from society can force companies to critically come to terms with the problem of identifying and implementing 'responsible behaviour'. And in fact 'Heightened corporate attention to CSR has not been entirely voluntary. Many companies awoke to it only after being surprised by public responses to issues they had not previously thought were part of their business responsibilities ${ }^{\prime}$.

On the other hand, it is time for mental attitudes to change, and for people to learn to move on a strategic level to identify a positive and winning approach to the issues of ethics and corporate social responsibility. Ethical 'proclamations', as lofty as they are unfeasible, which translate into cosmetic behaviour, permeated with superficiality, often adopted by organisations with the sole scope of creating or building an image, are of no use to the company or to society ${ }^{7}$.

In the paper quoted, Porter states that the four prevailing schools of thought that justify CSR (moral obligation, sustainability, licence to operate and reputation) cannot be considered satisfactory because '... they focus on the tension between business and society, rather than on their interdependence. Each creates a generic rationale that is not tied to the strategy and operations of any specific company or the places in which it operates ${ }^{8}$. He therefore proposes thinking in terms of 'corporate social integration (rather than responsibility). This integration, designed to create values that are shared by business and the civil society, cannot be applied indiscriminately ${ }^{9}$, but only by identifying a number of social problems to which 
business is able to make a significant contribution and from which it can also obtain the greatest competitive advantage.

The idea of evolving the concept of 'social responsibility' towards the 'integration between the strategy of any specific company and the problems of the society in which it operates' appears entirely acceptable. It helps us to overcome the identification of 'social responsibility' with a charitable approach, with (more or less significant) support to specific social causes or the systematic management of the negative effects of the value chain. It suggests exploiting the positive effects of these activities and, above all, of identifying and implementing '... a small number of initiatives whose social and business benefits are large and distinctive ${ }^{10}$.

In other words, according to Porter, a 'socially integrated' company does not limit itself to incorporating in its strategies decisions designed to ensure that the activities making up its value chain do not harm society, but also seeks out and develops investments that can generate important benefits for society while increasing its competitive advantage and raising its performance.

Analysis of the examples that Porter uses to clarify his theories clearly reveals that they refer to the strategic planning of 'specific' measures that make it possible to solve social problems, and simultaneously lay the foundations to expand their business. Where these possibilities emerge, where 'social investments' also generate positive economic benefits for the organisation, or are instrumental to the development of its activities, the author believes that the 'social' element is incorporated into the creation of value for stockholders.

The company therefore pursues social integration by seeking (and implementing) synergies between the growth of society and the growth of its own business.

Porter's attitude to CSR is very significant, not only because of the personal charisma and scientific worth of this student of strategy, but above all for the clearly expressed idea of dealing with the problems of ethics and special responsibility not as superficial elements or cosmetic events, designed to give polish to the organisation, but rather as 'a long-term investment in future competitiveness', to be tackled and dealt with from an entrepreneurial perspective, that implements the company's strategic management.

However we have to admit this is not a new idea. The need to conceive relations with the many components of society as a vital condition to guarantee the viability of the organisation and, consequently, the need to develop winning relations with each of the parties involved in manufacturing activities, has been expounded in the work of our teachers, starting with Gino Zappa. On the other hand, considering the company as a system of economic forces (men and funds) has constituted the logical premise to assign strategic significance to the expectations and hopes of the parties that cooperate to achieve the manufacturing goals inherent in the different types of company.

A virtuous approach to the activities of a business (or rather, of businesses in general), which can be summed up as the search for long-term balance, for behaviour capable of creating and maintaining a fabric of stable, fruitful relations with the parties that surround the organisation, is a key element of Italian business.

To confirm this, we must bear in mind the concept of 'economic-ness' (or economic productivity) proposed by Onida, as a firm's aptitude to remunerate 
manufacturing factors permanently and conveniently to keep them closely aligned to its own economy ${ }^{11}$.

This conception includes conditions conducive to behaviour that produces benefits not only for stockholders, but for all the parties that interact with the organisation or are part of it; the organisation is a hub for the creation of wealth for the entire community. On the other hand, irresponsible behaviour has negative repercussions in terms of jobs lost and harm done to different categories of parties involved.

The phrase 'convenient remuneration of the manufacturing factors' must be suitably interpreted in a modern key in order to define its meaning and understand its significance. Obviously we are not referring just to 'monetary remuneration' of the parties that guarantee the availability 'of manufacturing factors' (workers, suppliers of goods and services, financiers bound by constraints of ownership or loans), because this approach would be typical of a purely contractual relationship. On the contrary, we refer to the manner in which the fabric of relationships between the parties listed above and customers should develop, relationships that should evolve according to cooperative (collaborative) logics, establishing a close, permanent dialogue with these parties, designed to create knowledge and to establish the conditions for the relationships to evolve.

It is easy to observe that the conceptual dimension that emerges from the teachings of our doctrine is of far greater impact than the concepts that Porter arrived at in his latest paper on the subject. Porter limits social integration to situations in which specific convenience emerges for the company in each of the activities that make up the value chain: these situations consider investments that make it possible to leave one's mark on society, but also to improve the performance of the organisation.

If we look closely, investing in certain activities that can foster social development but are simultaneously able to increase corporate profitability, is more an expression of a competitive strategy, which identifies and pursues any business opportunities that present themselves, than the expression of a process designed to integrate business and society.

The importance and significance of the theories that we have briefly summarised as the heritage of our view of business are very different: the manufacturing organisation focuses its strategic vision on the inescapable need to suitably and stably examine the expectations of the parties that collaborate with it in the conduction of its manufacturing activities. Employees, suppliers, financiers, customers and society are the interlocutors with whom it is indispensable to create the organisation's future, organising and maintaining relationships based on collaboration and partnership at all stages of value creation.

Investing in stable and profitable relations with the parties listed above is a strategic choice that makes it possible to move to seek a lasting equilibrium, to obtain profits compatible with survival, and to promote the image; it also makes it possible to refuse short-term logics, the striving for maximum profit for the controlling capital and the externalisation of costs and losses over every other party.

True social integration is not achieved only by implementing strategies that simultaneously pursue the goals of rendering a service to society and achieving 
economic benefits for business. In fact, the implementation of these specific strategic choices, which seem to be competitive strategies, could easily coexist with absolutely irresponsible behaviour towards employees, minority stockholders, financiers, suppliers and customers who are marginalized in various ways by the organisation's goals.

Social integration is achieved if and to the extent that the organisation's strategic logics include behaviour designed to create every possible synergy between the parties that share responsibility for the manufacturing function in the broadest sense of the term. This behaviour makes it possible to raise the levels of awareness and performance and this would certainly have economic, cultural and social benefits that would determine not only an increase in profitability, but would also affect parties involved in any way in the organisation's activities.

As a result, profits would increase in a long-term perspective and a dimension that is not exclusive but compatible with the systematic improvement of the conditions of all parties and of society.

It therefore appears necessary to separate lines of behaviour which often tend to overlap and merge.

a) The ability to identify specific activities along the value chain that can have positive benefits for the social fabric and, simultaneously, can increase business volumes and corporate profits, has little connection with a correct conception of social integration (responsibility) that is an aspect of 'how to run a company' or, if we prefer, 'how to create value'.

b) This is why it is important that the basic strategic orientation and strategic behaviour of a company should include an aptitude to maintain stable and satisfactory cooperative relationships with all the parties involved in manufacturing activities. Both economic entities and those exercising an entrepreneurial function must be aware that this behaviour creates knowledge, makes manufacturing organisations socially liable and integrates them in society.

c) The decision to earmark resources (part of profits) for initiatives that benefit some components of society or that achieve important programmes to protect or restore works of art, monuments and archaeological sites, etc., is certainly commendable. However, these are worthy works that are not inherent in the nature and purpose for which companies are created, but come under the category of choices (individual and group) to earmark a portion of current assets to help the needy, to protect the cultural heritage of the community, and so on.

However, we cannot accept that this behaviour, no matter how desirable, useful or deserving, should replace that outlined at point b) above, which is much more weighty in terms of commitment and complexity. In so many cases, programmes implemented in the welfare field or to protect and defend our artistic or environmental heritage, prove to be aimed exclusively at improving the image of the company that implements them, whereas the need to adopt 'virtuous' behaviour in relation to workers, other organisations and the natural environment, have no place whatsoever in the strategic orientation of the same organisations, which 
remain 'irresponsible' in the 'way they do business', even if they do dedicate some of their resources to socially useful activities.

Even the recent and authoritative declarations regarding social responsibility (or integration), which may on one hand do justice to a type of behaviour that is firmly oriented to mere image creation, still do not go to the heart of the problem, appearing narrow and open to strong criticism.

The need to make the shareholder theory operative, a logic that Porter's doctrine seems to uphold, is probably not easily reconciled with a concept of social responsibility that is integrated in all the behaviour and activities that make up the value chain. Our purpose is to underline how difficult it is in real behaviour, over and above any theoretical pronouncements, to combine the 'creation of value for stockholders', viewed as the company's sole objective, with the need to create value for the other stakeholders. The creation of value for stockholders cannot be the sole objective for which a company is established; a company must direct its activities to the creation of value for itself and for the different stakeholders involved in any way in the production process, guaranteeing conditions of economic and financial equilibrium, and maintaining positions of strategic equilibrium in relation to the various interlocutors and the markets.

\section{Bibliography}

Ianneo F., La questione dei valori tra filosofia e biologia, AA.VV., Polis ed Ethos, Edizioni Scientifiche Italiane, Rome, 2000.

Lai A., Paradigmi interpretativi dell'impresa contemporanea. Teorie istituzionali e logiche contrattuali, Franco Angeli, Milan, 2004, p. 193.

Onida P., Economia d'azienda, Utet, Turin, 1971.

Porter M. E., Kramer M.R., Strategy \& Society. The Link Between Competitive Advantage and Corporate Social Responsibility, Harvard Business Review, December 2006.

Rappaport A., Ten Ways to Create Shareholder Value, Harvard Business Review, 2006.

Rossi G., Il conflitto epidemico, Adelphi, Milan, 2003, p. 19.

\section{Notes}

${ }^{1}$ Supra-historical ethics based on '.. abstract moral theorems... has produced as an inevitable consequence, a divorce from the rationale of life which is actually always contextual and contingent'. (see F. IANNEO, La questione dei valori tra filosofia e biologia, in AA.VV., Polis ed Ethos, Edizioni Scientifiche Italiane, Rome, 2000).

${ }^{2}$ Rossi G., Il conflitto epidemico, Adelphi, Milan, 2003, p. 19.

${ }^{3}$ Cf. Rappaport A., Ten ways to create Shareholder Value, Harvard Business Review, 2006.

${ }^{4}$ See Lai A., Paradigmi interpretativi dell'impresa contemporanea. Teorie istituzionali e logiche contrattuali, Franco Angeli, Milan, 2004, p. 193.

${ }^{5}$ See Porter M. E. - Kramer M. R., Strategy \& Society. The Link Between Competitive Advantage and Corporate Social Responsibility, Harvard Business Review, December 2006. 
${ }^{6} \mathrm{i}$ bid.

7 'In fact, the most common corporate response has been neither strategic nor operational but cosmetic', ibid.

${ }^{8} \mathrm{i}$ bid.

9 'The short-term performance pressures companies face rule out indiscriminate investments in social value creation.' 'Companies are not responsible for all the world's problems, nor do they have the resources to solve them all', ibid.

${ }^{10} \mathrm{i}$ bid.

${ }^{11}$ Cf. Onida P., Economia d'azienda, Utet, Turin, 1971. 